\title{
Perfil dos estudantes de graduação entre 2001 e 2015: uma revisão
}

\author{
Profile of undergraduate students between 2001 and 2015: a review
}

Ana Luíza Matos de Oliveira ${ }^{1}$

Resumo: Em uma perspectiva multidimensional quanto à desigualdade, o artigo objetiva verificar se a literatura e as bases de dados comumente utilizadas permitem identificar uma democratização do acesso à educação superior entre 2001 e 2015 e se há alguma lacuna nos estudos que analisam o perfil dos estudantes de graduação no período. O artigo é composto por introdução, revisão da literatura, panorama dos principais bancos de dados e pesquisas realizadas sobre o perfil dos estudantes e finaliza identificando possíveis lacunas e agendas de pesquisa futuras. Conclui-se que a literatura aponta uma democratização do perfil dos estudantes, mas falta uma comparação anual dos estudantes do setor público e privado conjuntamente quanto a cor/raça, renda e região, que poderia ser construída a partir da PNAD.

Palavras-chave: Educação superior. Desigualdades socioeducacionais. Perfil dos estudantes. 
Abstract: In a multidimensional perspective regarding inequality, the article aims to verify whether the literature and commonly used databases allow to identify a democratization of access to higher education between 2001 and 2015 and if there is any gap in the studies that analyze the profile of undergraduate students in the period. The article consists of introduction, review of the literature, overview of the main databases and research on the profile of the students and concludes by identifying possible gaps and future research agenda. The literature points to a democratization of the student profile. However, there is a lack of an annual comparison of students from the public and private sectors together regarding color / race, income and region, which could be built from PNAD.

Keywords: Higher Education. Socioeducational inequalities. Profile of students.

Faculdade Latino-Americana de Ciências Sociais Brasil | São Paulo | SP | Brasil. Contato: almatosdeoliveira@gmail.com. ORCID: http://orcid.org/ 0000-0002-9623-3305

- Recebido em: 23 de abril de 2020

- Aprovado em: 13 de novembro de 2020

DOI: http://dx.doi.org/10.1590/S1414-40772021000100013

Este é um artigo publicado em acesso aberto sob uma licença Creative Commons https://creativecommons.org/licenses/by-nc/4.0/ 


\section{Introdução}

O início do século XXI, em especial entre 2001 e 2015, é interpretado por diversos especialistas como um momento de crescimento, redistribuição de renda e melhorias sociais, que alia o arcabouço da "Constituição Cidadã” (a Constituição Federal de 1988) a um aumento de orçamento para a questão social, aumento do investimento público e a realização de políticas públicas de corte transversal (FAGNANI, 2017). Com este quadro, foi possível reduzir a pobreza, ampliar a ocupação (especialmente a formalizada) e reduzir as desigualdades da renda do trabalho. Nos interessa entender melhor características deste período e as mudanças ocorridas na sociedade brasileira. O recorte em 2015 ocorre devido à adoção da austeridade fiscal a partir deste ano e da crise econômica que se instala no país (OLIVEIRA, 2019).

Sobre a redução das desigualdades entre 2001 e 2015, adotamos a perspectiva multidimensional de Campello (2017), que pondera que não só a desigualdade de renda importa, mas o acesso aos direitos sociais é parte importante da desigualdade social. Neste sentido, nos interessa especificamente mapear se e como, neste período, houve uma democratização do acesso à educação superior, refletido na mudança do perfil dos estudantes que acessam a Educação Superior (ES). A ES é um item muito importante para analisar as desigualdades de forma mais ampla no país, pois o Brasil é um dos países com maior retorno à educação superior em todo o mundo, ou seja, ter acesso à educação superior representa um salto bastante significativo na renda do egresso, muito mais significativo que em outros países que apresentam menor desigualdade (OCDE, 2018).

Neste artigo, é feita uma revisão da literatura e das bases de dados que discutem uma mudança do perfil dos estudantes no início do século XXI, mais especificamente entre 2001 e 2015. Busca-se mapear quais são os impactos das políticas públicas adotadas pelo Brasil durante o início do século XXI (como Prouni, Reuni, Ações Afirmativas, FIES, a ampliação da assistência estudantil, entre outras) para a ES no perfil dos estudantes de graduação no Brasil segundo a literatura e as bases de dados existentes. O objetivo do artigo é verificar se a literatura e as bases de dados existentes permitem identificar uma democratização do acesso à educação superior e se há alguma lacuna nos estudos que analisam o perfil dos estudantes da ES entre 2001 e 2015.

Neste ponto, alguns esclarecimentos fazem-se necessários. Em primeiro lugar, ao nos referirmos a democratização na ES nos referimos ao processo de aproximar socioeconomico, racial e espacialmente o perfil dos estudantes da ES ao da população brasileira, reduzindo as desigualdades de acesso à ES. Neste sentido, nos aproximamos do conceito de Dubet (2015) de 
democratização do acesso, que trata de uma ampliação dos grupos sociais com acesso à massificação da ES; e menos do conceito do mesmo autor de democratização interna, que se refere às diferenças existentes dentro da ES; ou do conceito de utilidades acadêmicas também do mesmo autor, que se referem ao valor do título no mercado de trabalho. Apesar de todas as três dimensões serem fundamentais, o enfoque neste artigo é no primeiro sentido do conceito. Em segundo lugar, Educação Superior é definida no artigo como nível de ensino não compulsório após o ensino médio, realizado em Instituições de Educação Superior (IES), não incluindo o ensino técnico. Estudantes são definidos como aqueles que se declaram ou são matriculados em cursos de graduação.

O artigo é composto por esta introdução, uma revisão da literatura mais recente sobre o tema, um panorama dos principais bancos de dados e pesquisas realizadas sobre o perfil dos estudantes no período analisado e finaliza nas conclusões identificando possíveis lacunas e agendas de pesquisa futuras.

\section{Revisão da literatura}

De maneira geral, a literatura aponta que houve um processo de democratização no acesso durante os anos 2000. Por exemplo, Guimarães et al. (2010) analisa que as políticas de expansão do acesso à Educação Superior (ES) nos anos 2000 relaxaram a associação entre background socioeconômico e chances de entrada nesse nível, em especial no caso das metrópoles brasileiras e com implicações na possibilidade de mobilidade social. Na mesma linha, houve uma inclusão significativa de grupos vulneráveis na universidade (COSTA et al., 2011; IBGE, 2014; RISTOFF, 2014), com a criação de novos cursos, novas universidades. Outro efeito da interiorização de IES é o desenvolvimento regional.

Sobre a distribuição espacial dos estudantes, segundo Mazza (2015), a educação tem o potencial de transformar cidades em um polo de atração e circulação de tipos específicos de pessoas, saberes, capitais, produções e práticas, tendo grande potencial de alteração das dinâmicas regionais, como efetivamente ocorreu no período analisado. Sobre a desigualdade regional, Vieira (2016) também abaliza que desconcentrar as atividades de ensino e pesquisa, como ocorreu nos anos 2000, tem impacto nos processos de decisão privada locacional de atividades intensas em ciência e tecnologia, por exemplo, abrindo perspectivas de desenvolvimento regional importantes e capacidade de gerar processos cumulativos de aglomeração. Mas, apesar dos avanços, ainda há muita concentração: segundo Vieira (2016), em $2014,57 \%$ dos equipamentos relativos à ciência e tecnologia no país estavam concentrados 
na região Sudeste e 24\%, no Sul. Sul e Sudeste também concentravam em 2010 mais de 72\% da produção científica do país, enquanto concentravam também $85,7 \%$ dos pedidos de patentes nacionais em 2013. No entanto, o autor conclui que a expansão do sistema de ES brasileiro nos anos 2000 ocorreu de forma relativamente menos concentrada em termos territoriais, sendo também um elemento promissor para um ciclo de desenvolvimento regional menos assimétrico.

Sobre cor/raça, também houve avanços nos últimos anos como fruto das políticas adotadas, em especial a expansão das instituições federais de educação superior, a política de ações afirmativas e o Prouni. Considerando o total da população brasileira, Carvalho (2014) analisa que em 1997, somente 2,2\% dos pardos e 1,8\% dos pretos brasileiros cursavam ou portavam o diploma de graduação, enquanto em 2013 esse número subiu para 11\% dos pardos e $8,8 \%$ dos pretos. Também, segundo Feres Júnior (2013), considerando o total de estudantes das universidades federais, houve aumento da presença de negros: em 2003, os pretos representavam 5,9\% dos estudantes e os pardos 28,3\%, enquanto em 2010 esses números subiram para $8,72 \%$ e $32,08 \%$ respectivamente.

Sobre a renda, Campello (2017) calcula que, na população como um todo, o percentual de jovens de 18 a 24 anos que frequenta a ES (contando nesse cálculo os matriculados em mestrado e doutorado) cresceu de 9,9\% para $18 \%$ de 2002 a 2015. Mas uma análise mais detalhada mostra que essa ampliação do acesso ocorreu com melhorias em especial para a população mais pobre: em 2002, 0,3\% dos jovens dessa faixa etária entre os $20 \%$ mais pobres frequentavam ES e tal percentual passou para 4,7\% em 2015. Já entre os 5\% mais pobres, esse número passou de 0,2\% em 2002 para 2,5\% em 2015. Ainda, em termos regionais, o acesso à ES se ampliou ainda mais nas regiões Norte e Nordeste (crescendo respectivamente 197\% e $142 \%$ no intervalo analisado), regiões com taxa de matrícula bruta mais baixas que o resto do país, o que ajudou a reduzir as desigualdades regionais durante esse período.

Também Andifes (2016) mostra que, em 2016, os estudantes das Instituições Federais de Educação Superior (IFES) tinham um perfil mais popular: 66,19\% era proveniente de famílias com renda per capita de até 1,5 SM (em 2010 eles eram 44\%). E que, em 2016, 53\% dos estudantes usam transporte público para ir à IES, 11,78\% tem filhos, 60,16\% estudaram em escola pública, $35,9 \%$ trabalham pelo menos 20 horas por semana e $65,34 \%$ dos estudantes tem nível de escolaridade mais alto que o de suas mães.

Feito este panorama, passamos ao mapeamento das bases de dados comumente utilizadas para traçar o perfil dos estudantes da educação superior. 


\section{Bases de dados}

\subsection{Fonaprace: mudança no perfil de cor, raça e renda dos estudantes nas IFES}

Sobre o perfil dos estudantes, um dos importantes estudos nessa área é a pesquisa da Andifes/Fonaprace sobre o Perfil Socioeconômico dos Estudantes das IFES brasileiras. Pesquisa amostral, se baseia na auto-aplicação do instrumento de coleta de dados (cada estudante se aplica o questionário). Atualmente, a Pesquisa se encontra na quinta edição, mas os últimos dados disponíveis no seu site (FONAPRACE, 2014), referentes ao final de 2014, dão dimensão das transformações ocorridas na ES nos últimos anos, tendentes à democratização de seu acesso, em especial nas IFES. A pesquisa, por conter dados do final do ano de 2014, é um bom retrato do Brasil às vésperas da adoção da política de ajuste fiscal e da crise do mercado de trabalho que ocorre a partir do início de 2015. Ela, no entanto, se limita às IFES.

Segundo dados da pesquisa, em 1996 as mulheres representavam 51,4\% das graduandas, passando a 53\% em 2003, 53,5\% em 2010 e 52,3\% em 2014. Esses dados, que são reforçados por melhores indicadores de acesso à educação como um todo pelas mulheres, não significa que não exista ainda uma divisão de áreas de conhecimento dentro das IES, com as mais valorizadas tendo maior concentração de homens; nem significa que as mulheres tenham alcançado postos de liderança dentro das IES em igual proporção aos homens; e nem significa que no mercado de trabalho não exista discriminação de gênero.

Mas as mudanças mais significativas no perfil dos estudantes das IFES, segundo a pesquisa, são relativas à idade, cor/raça e renda. Sobre o primeiro item, a idade média dos estudantes de graduação, que se mantinha estável em cerca de 23 anos desde a primeira pesquisa até 2010, elevou-se para cerca de 24,5 anos em 2014.

Quanto à cor/raça, o perfil dos graduandos muito mudou nas IFES ao longo dos anos analisados, como mostra a Tabela 1. Os brancos passaram a representar menor fatia dos graduandos ao longo dos anos, seja para os dados das IFES, seja na população brasileira (como mostram os dados da Pnad/Censo na Tabela 1). Pelos dados das IFES, de 2003 a 2014 sua participação caiu de 59,4\% para 45,67\% . Já os pardos passaram de $28,3 \%$ dos graduandos em IFES em 2003 para 37,75\% em 2014. E os pretos passaram de 5,9\% dos graduandos em 2003 para 9,82\% dos graduandos em 2014. Entre os indígenas os dados das IFES mostram uma redução de sua participação de 2\% em 2003 para 0,64\% em 2014. 
Tabela 1 - Percentual de graduandos e população brasileira segundo Cor ou Raça, \%, (1996 - 2014)

\begin{tabular}{|c|c|c|c|c|c|}
\hline Cor/Raça & Pesquisa & 1996 & 2003 & 2010 & 2014 \\
\hline \multirow[t]{2}{*}{ Amarela } & Graduandos - IFES & \multirow{2}{*}{$\begin{array}{c}- \\
0,42 \\
\end{array}$} & \multirow{2}{*}{$\begin{array}{c}4,5 \\
0,44 \\
\end{array}$} & 3,06 & 2,34 \\
\hline & População - PNAD/Censo & & & 1,09 & 0,49 \\
\hline \multirow[t]{2}{*}{ Branca } & Graduandos - IFES & \multirow{2}{*}{$\begin{array}{c}- \\
55,24 \\
\end{array}$} & \multirow{2}{*}{$\begin{array}{c}59,4 \\
51,96 \\
\end{array}$} & 53,93 & 45,67 \\
\hline & População - PNAD/Censo & & & 47,73 & 45,58 \\
\hline \multirow[t]{2}{*}{ Parda } & Graduandos - IFES & \multirow{2}{*}{$\begin{array}{c}- \\
38,19 \\
\end{array}$} & \multirow{2}{*}{$\begin{array}{c}28,3 \\
41,47 \\
\end{array}$} & 32,08 & 37,75 \\
\hline & População - PNAD/Censo & & & 43,13 & 45,05 \\
\hline \multirow[t]{2}{*}{ Preta } & Graduandos - IFES & \multirow{2}{*}{$\begin{array}{c}- \\
5,97 \\
\end{array}$} & \multirow{2}{*}{$\begin{array}{c}5,9 \\
5,93 \\
\end{array}$} & 8,72 & 9,82 \\
\hline & População - PNAD/Censo & & & 7,61 & 8,58 \\
\hline \multirow[t]{2}{*}{ Indígena } & Graduandos - IFES & \multirow{2}{*}{$\begin{array}{c}- \\
0,16\end{array}$} & \multirow{2}{*}{$\begin{array}{c}2 \\
0,19 \\
\end{array}$} & 0,93 & 0,64 \\
\hline & População - PNAD/Censo & & & 0,43 & 0,4 \\
\hline \multirow[t]{2}{*}{ Outra } & Graduandos - IFES & \multirow{2}{*}{$\begin{array}{l}- \\
- \\
\end{array}$} & \multirow{2}{*}{$\begin{array}{l}- \\
- \\
\end{array}$} & 1,28 & - \\
\hline & População - PNAD/Censo & & & - & - \\
\hline \multirow[t]{2}{*}{ Sem declaração } & Graduandos - IFES & \multirow{2}{*}{$\begin{array}{c}- \\
0,02\end{array}$} & \multirow{2}{*}{$\begin{array}{l}- \\
0\end{array}$} & \multirow[b]{2}{*}{0} & 3,78 \\
\hline & População - PNAD/Censo & & & & 0 \\
\hline
\end{tabular}

Fonte: PNAD/IBGE e Fonaprace (FONAPRACE, 2014).

Segundo Fonaprace (2014), a mudança do perfil estudantil por cor/raça poderia ter ocorrido pelo amplo movimento de reinterpretação do processo de autodeclaração na sociedade brasileira nos anos recentes, com os estudantes mudando sua visão sobre sua cor/raça de branca para preta ou parda. No entanto, pela magnitude e velocidade da mudança, tal fenômeno não pode ser devido somente à mudança na autodeclaração, mas está relacionado também ao significativo papel de outras mudanças sociais e de mudanças na própria estrutura das IFES, quais sejam, melhorias no mercado de trabalho e as políticas públicas implementadas e discutidas no capítulo 2.

Sobre a renda bruta familiar dos graduandos das IFES, a pesquisa mostra que, em 2010, 8,33\% era a porcentagem de estudantes com renda bruta familiar de até 1 Salário Mínimo (SM). Esse percentual passa a 13,21\% em 2014. Os estudantes com renda bruta familiar de até 2 SM passaram de $26,47 \%$ para $36,65 \%$ no mesmo período. E os estudantes com renda bruta familiar de até 3 SM passaram de 40,66\% para 51,66\% dos estudantes no mesmo período. No outro extremo, os estudantes com renda bruta familiar de mais de 10 SM passaram de 16,72\% em 2010 para 10,5\% em 2014. Já considerando a renda bruta familiar per capita, os dados mostram que, em 2014, 31,97\% dos estudantes de IFES tinham renda bruta familiar per capita de até 1/2 SM, 53,93\% até 1 SM, 66,19\% até 1,5 SM e 78,44\% até 2 SM. São alvo prioritário dos Programas de Assistência Estudantil das IFES os estudantes com renda familiar per capita de até 1,5 SM, ou seja, mais de $66 \%$ dos graduandos das IFES brasileiras, alcançando mais de $76 \%$ dos graduandos das regiões Norte e Nordeste.

Os dados da pesquisa mostram como o acesso às IFES se transformou em termos de idade, raça e renda nos últimos anos. Assim, em 2014, segundo o documento, "as IFES agora 
se acham mais parecidas com o restante da sociedade. Uma realidade bem distinta até da vigente há 4 anos atrás" (FONAPRACE, 2014:5, grifo nosso).

\subsection{Censo da Educação Superior e ENADE: mudança no perfil de cor/raça e regional dos estudantes das IES}

Os dados que constam no Censo da Educação Superior (realizado pelo Instituto Nacional de Estudos e Pesquisas Educacionais Anísio Teixeira - INEP) auxiliam a entender o movimento do perfil dos estudantes de ES a partir da cor/raça, além dos movimentos regionais, que podem ser percebidos pela evolução da taxa bruta de matrícula, como veremos mais à frente. Ponderamos que as informações para cor/raça só estão disponíveis no Censo da Educação Superior a partir de 2009.

O Censo da Educação Superior se refere a dados de todas as Instituições de Ensino Superior (IES) do país, sejam públicas ou privadas, federais, estaduais ou municipais, marcando uma diferença com os dados da Fonaprace apresentados na seção anterior. Ele é obtido através de respostas das Instituições de Educação Superior do país: Universidades, Centros Universitários, Faculdades Integradas, Faculdades, Escolas ou Institutos Superiores e Centros de Educação Tecnológica, que possuem um ou mais cursos com data de início de funcionamento até 30 de outubro do ano base do levantamento.

Sobre a categoria de cor/raça, dados do Censo da Educação Superior apontam que de 2011 a 2017 aumentou o percentual de negros na ES: de 12\% para 32,5\%. Nas IES públicas, passou de 16,3\% para 38,4\%. E nas IES privadas, passou de 10,4\% para 30,5\%, como mostra a Tabela 2. O período também coincide com a implementação de diversas políticas públicas com o objetivo de ampliar a inclusão social na ES, como a política de cotas, o Prouni e o Reuni (que criou novas universidades, expandiu cursos e criou cursos noturnos).

Percebe-se uma melhoria dos dados, pois há uma redução da quantidade de estudantes cuja cor/raça é desconhecida (não declarada ou não dispõe de informação): 2,3 milhões saíram dessa categoria. Por outro lado, como mostra a Tabela 3, o aumento do número de matrículas foi de 1,5 milhões de 2011 a 2017, sendo em torno de 270 mil nas IES Federais e 1,2 milhões nas IES privadas.

Entre os brancos, o aumento das matrículas foi de 1,8 milhão no período analisado e entre negros (pretos e pardos) de 1,9 milhão, o que é um indicativo de que o aumento do acesso à ES de 2011 a 2017 ocorreu com um aumento da democratização na ES em termos de cor/raça, acompanhando melhor o perfil da população brasileira. 


\section{Tabela 2 - Matrículas em cursos de graduação presenciais e à distância por cor/raça e tipo de IES (2011, 2014 e 2017)}

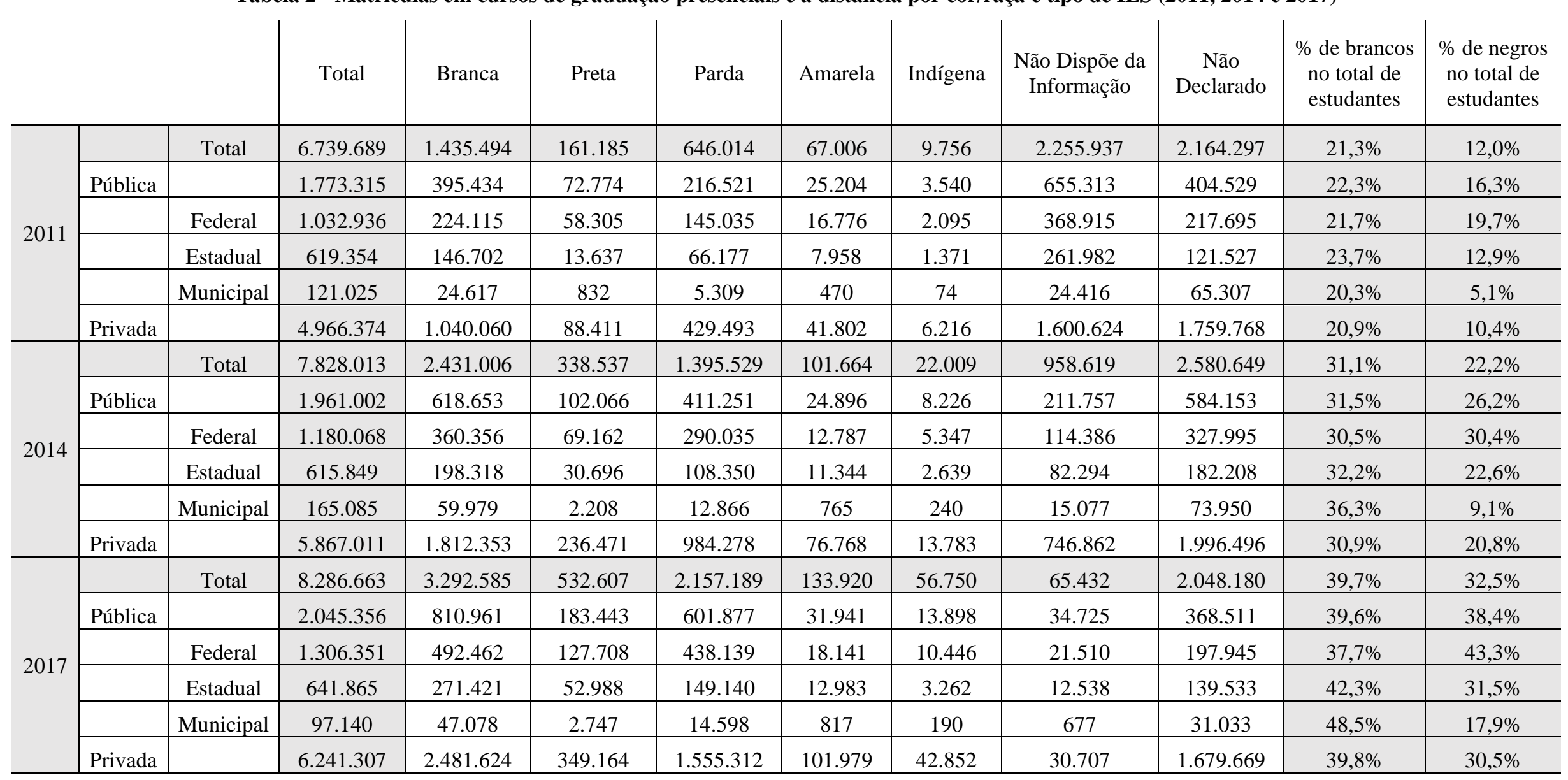

Fonte: Elaboração própria a partir do Censo da Educação Superior, 2011 e 2017. 
Tabela 3 - Variação do perfil dos estudantes por cor e tipo de IES (2011 - 2017)

\begin{tabular}{|c|c|c|c|c|c|c|c|c|}
\hline & 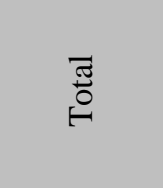 & 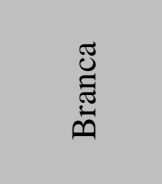 & $\frac{\pi}{0}$ & 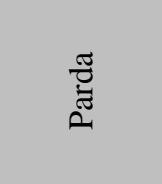 & 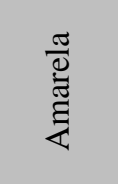 & 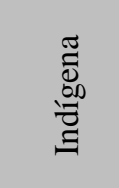 & 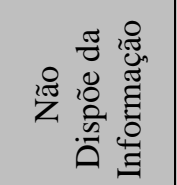 & 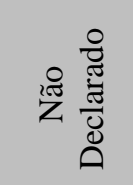 \\
\hline $\begin{array}{l}\text { Aumento total } \\
(2011-2017)\end{array}$ & 1.546 .974 & 1.857 .091 & 371.422 & 1.511 .175 & 66.914 & 46.994 & -2.190 .505 & -116117 \\
\hline $\begin{array}{c}\text { Aumento IES } \\
\text { Federal }\end{array}$ & 272.041 & 415.527 & 110.669 & 385.356 & 6.737 & 10.358 & 620.588 & -36018 \\
\hline $\begin{array}{c}\text { Aumento IES } \\
\text { Privada }\end{array}$ & 1.274 .933 & 1.441 .564 & 260.753 & 1.125 .819 & 60.177 & 36.636 & 1.569 .917 & -80099 \\
\hline
\end{tabular}

Fonte: Elaboração própria a partir do Censo da Educação Superior, 2011 e 2017.

Fizemos então uma análise dos dados de Taxa Bruta de Matrícula (TBM), definida segundo metodologia UIS - Unesco como:

$$
\frac{\text { Quantidade de graduandos (INEP) }}{\text { Quantidade de jovens de } 18 \text { a } 22 \text { anos no Brasil (PNAD e PNADC) }}
$$

Em primeiro lugar, a TBM passou de 0,13 em 1995 para 0,22 em 2003, 0,28 em 2007, 0,36 em 2011, 0,39 em 2014 e 0,40 em 2016.

A TBM das mulheres é mais alta no Brasil que a dos homens: respectivamente 0,26 e 0,19 em 2003, subindo para 0,46 e 0,35 em 2016, o que não significa que as mulheres estejam em vantagem em relação aos homens na sociedade. A este respeito, a literatura aponta que quanto maior a escolaridade, maior são as desigualdades de gênero (OLIVEIRA, 2019), o que mostra que a variável de gênero também é importante para entender as desigualdades que permeiam a ES: apesar de as mulheres brasileiras apresentarem melhores indicadores educacionais que os homens, as desigualdades se reproduzem nas áreas de concentração e no mercado de trabalho.

As maiores disparidades na TBM ainda continuam sendo quanto à cor/raça: considerando matrículas em cursos presenciais e EaD, a partir de dados da Pnad e do Inep, a TBM dos negros (pretos e pardos) era de 0,09 em 2011, contra 0,20 dos brancos. Esse número sobe para 0,18 para negros em 2014 e 0,35 para brancos. Já em 2016, sobe para 0,25 entre os negros e 0,47 entre os brancos. A diferença da TBM aumenta entre os grupos de 0,10 em 2011, para 0,16 em 2014 e 0,22 em 2016, pois aumenta a matrícula de estudantes negros no Brasil, mas a população negra (por mudanças na autodeclaração como discutido anteriormente ou pela própria dinâmica populacional) aumenta a um ritmo maior que a população branca. 
Para analisar as mudanças da TBM em termos regionais, compilamos os resultados em uma tabela. Destaca-se na Tabela 4, bem visivelmente, o valor alto das TBM encontradas no Distrito Federal em relação a todas as outras UFs.

Tabela 4 - Taxa bruta de matrícula em cursos presenciais por Unidade da Federação, Brasil (1995, 2003, 2007, 2011, 2014 e 2016)

\begin{tabular}{|c|c|c|c|c|c|c|}
\hline UF ou Região/Ano & 1995 & 2003 & 2007 & 2011 & 2014 & 2016 \\
\hline Rondônia & 0,08 & 0,30 & 0,22 & 0,29 & 0,31 & 0,32 \\
\hline Acre & 0,10 & 0,25 & 0,27 & 0,32 & 0,36 & 0,37 \\
\hline Amazonas & 0,07 & 0,28 & 0,29 & 0,37 & 0,38 & 0,38 \\
\hline Roraima & 0,09 & 0,12 & 0,25 & 0,47 & 0,40 & 0,44 \\
\hline Pará & 0,12 & 0,13 & 0,12 & 0,15 & 0,19 & 0,20 \\
\hline Amapá & 0,08 & 0,25 & 0,29 & 0,32 & 0,40 & 0,53 \\
\hline Tocantins & 0,04 & 0,25 & 0,24 & 0,34 & 0,40 & 0,38 \\
\hline Maranhão & 0,04 & 0,09 & 0,11 & 0,15 & 0,20 & 0,22 \\
\hline Piauí & 0,04 & 0,18 & 0,20 & 0,33 & 0,35 & 0,38 \\
\hline Ceará & 0,06 & 0,11 & 0,14 & 0,23 & 0,29 & 0,34 \\
\hline Rio Grande do Norte & 0,08 & 0,15 & 0,19 & 0,33 & 0,33 & 0,38 \\
\hline Paraíba & 0,11 & 0,14 & 0,19 & 0,32 & 0,36 & 0,41 \\
\hline Pernambuco & 0,10 & 0,13 & 0,19 & 0,26 & 0,29 & 0,30 \\
\hline Alagoas & 0,05 & 0,12 & 0,15 & 0,27 & 0,25 & 0,26 \\
\hline Sergipe & 0,07 & 0,14 & 0,19 & 0,29 & 0,33 & 0,36 \\
\hline Bahia & 0,05 & 0,10 & 0,15 & 0,23 & 0,25 & 0,27 \\
\hline Minas Gerais & 0,11 & 0,20 & 0,30 & 0,34 & 0,40 & 0,41 \\
\hline Espírito Santo & 0,10 & 0,23 & 0,29 & 0,35 & 0,39 & 0,40 \\
\hline Rio de Janeiro & 0,18 & 0,32 & 0,39 & 0,44 & 0,45 & 0,47 \\
\hline São Paulo & 0,20 & 0,28 & 0,37 & 0,46 & 0,51 & 0,48 \\
\hline Paraná & 0,13 & 0,30 & 0,36 & 0,39 & 0,42 & 0,45 \\
\hline Santa Catarina & 0,16 & 0,31 & 0,37 & 0,39 & 0,46 & 0,46 \\
\hline Rio Grande do Sul & 0,21 & 0,33 & 0,39 & 0,44 & 0,47 & 0,48 \\
\hline Mato Grosso do Sul & 0,13 & 0,27 & 0,32 & 0,36 & 0,43 & 0,41 \\
\hline Mato Grosso & 0,09 & 0,23 & 0,29 & 0,38 & 0,50 & 0,48 \\
\hline Goiás & 0,09 & 0,27 & 0,29 & 0,37 & 0,38 & 0,39 \\
\hline Distrito Federal & 0,20 & 0,50 & 0,53 & 0,69 & 0,76 & 0,77 \\
\hline Norte & 0,09 & 0,20 & 0,20 & 0,25 & 0,29 & 0,30 \\
\hline Nordeste & 0,07 & 0,12 & 0,16 & 0,25 & 0,28 & 0,31 \\
\hline Sudeste & 0,17 & 0,26 & 0,36 & 0,42 & 0,46 & 0,46 \\
\hline Sul & 0,17 & 0,31 & 0,37 & 0,41 & 0,45 & 0,46 \\
\hline Centro-Oeste & 0,12 & 0,30 & 0,34 & 0,44 & 0,49 & 0,49 \\
\hline Brasil & 0,13 & 0,22 & 0,28 & 0,36 & 0,39 & 0,40 \\
\hline
\end{tabular}

Fonte: Elaboração própria a partir de PNAD e Censo da Educação Superior. 
De modo geral, os dados mostram um crescimento da TBM constante a expressivo desde os anos 90, mas que se acelera nos anos 2000. Por outro lado, os dados mostram que, após 2014, a única UF em que continua a crescer vertiginosamente a TBM é o Amapá. No Mato Grosso, Mato Grosso do Sul, São Paulo e Tocantins, há uma redução da TBM de um ano a outro, com a maioria das outras UFs apresentando indicadores estáveis.

Por fim, para melhor visualização, agrupamos as UFs nas 5 regiões do IBGE no Gráfico 1: de 1995 a 2014 os índices cresceram em quase todos os períodos para as regiões do Brasil, estacionando a partir de 2014, com crescimento ínfimo até 2016, em especial no Centro-Oeste e no Sudeste. Também se nota que a dispersão dos valores é maior ao fim do período (2016) que no início (1995), com o Sudeste, Sul e Centro-Oeste se destacando bem acima da média do Brasil e Norte e Nordeste ainda abaixo.

Gráfico 1 - Taxa bruta de matrícula em cursos presenciais por região e Brasil (1995 - 2016)

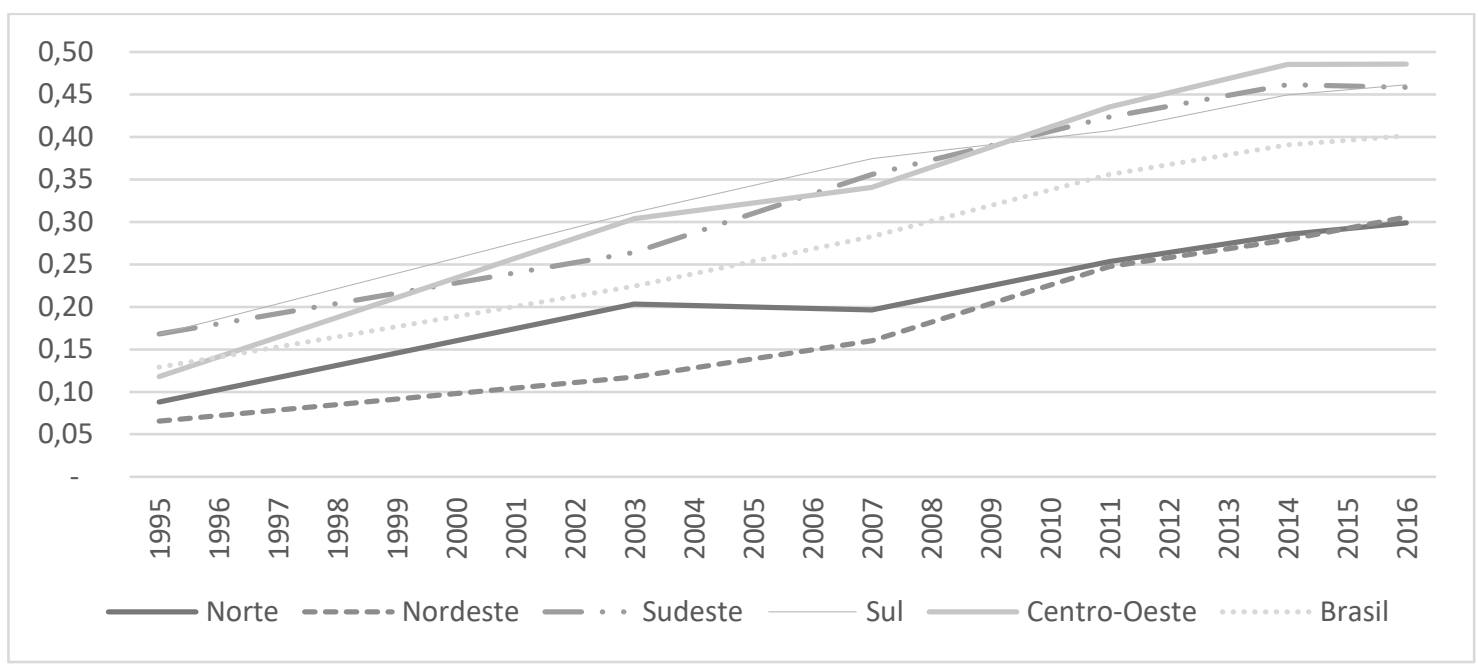

Fonte: Elaboração própria a partir de PNAD e INEP.

E, finalmente, os dados mais atualizados sobre o perfil dos concluintes são mostrados nos resultados do Exame Nacional de Desempenho dos Estudantes (ENADE) de 2017, realizado pelo Instituto Nacional de Estudos e Pesquisas Educacionais Anísio Teixeira (INEP), ligado ao Ministério da Educação (ENADE, 2018). O Exame, que substituiu o Exame Nacional de Cursos / "Provão" (OLIVEIRA; ARAUJO, 2005), engloba os concluintes de cursos em 2017, independentemente do tipo de instituição ao qual está vinculado, sendo mais abrangente que o perfil traçado pela pesquisa da Andifes/Fonaprace, com enfoque nas IFES. Essa pesquisa, no entanto, é amostral. Os dados são fornecidos pelos próprios estudantes. 
Uma questão fundamental abalizada pelos resultados do ENADE é que, entre os concluintes de cursos presenciais em $2017, \mathbf{3 3 , 2 \%}$ são os primeiros da família a ter um diploma de ES. Ainda, entre os estudantes concluintes em 2017, 51,7\% se declararam brancos, 9,4\% pretos, 2,4\% amarelos, 33,2\% pardos, $0,4 \%$ indígenas e 2,8\% não quiseram declarar. Quanto ao sexo, 55\% são do sexo feminino, mas alcança 77,3\% entre os concluintes de cursos na modalidade EaD. E 51,6\% dos concluintes em 2017, segundo a pesquisa, provém de famílias com renda de até $3 \mathrm{SM}$ e 72,1\% de famílias com renda de até 4,5 SM.

ENADE (2018) ainda indica que a concentração de estudantes de famílias com renda até 3 SM é maior entre os concluintes de cursos em modalidade EaD. Também entre os concluintes de cursos $\mathrm{EaD}, 14,9 \%$ afirmaram ser o principal responsável pelo sustento da família, porcentagem que cai para 7,7\% entre os concluintes de cursos presenciais. E 21,7\% dos concluintes afirmaram ter entrado na ES através de ações afirmativas.

Finalmente, 22,5\% do total de respondentes receberam financiamento do Prouni e/ou FIES (14,3\% somente FIES, 6,2\% Prouni integral, 1,2\% Prouni parcial apenas, 0,7\% Prouni parcial e FIES). Outros 7\% declararam receber bolsa da própria instituição e 14,3\% financiamento bancário, enquanto 33,3\% declarou que seu curso foi gratuito e 30,5\% declarou ter frequentado curso pago, mas não receber financiamento ou bolsa de estudo.

\section{Considerações finais}

Tanto os estudos apresentados neste artigo quanto as análises a partir das bases de dados específicas mostram que há uma mudança no perfil dos estudantes de graduação brasileiros (seja no setor público ou privado) quanto à raça/cor, renda e região, pelo menos até 2015, como possível resultado das políticas públicas adotadas no Brasil no início do século XXI, conjugadas a uma melhoria dos índices socioeconômicos e em especial com a melhoria no mercado de trabalho, que altera as decisões de gasto das famílias.

No entanto, este processo pode estar em risco desde o início da crise econômica (OLIVEIRA, 2019), com o impacto da crise no mercado de trabalho (GUERRA; SILVA; OLIVEIRA, 2017) e no orçamento das políticas públicas (ROSSI et al., 2019; ISTOÉ, 2018). Também, desde o final de 2018, assiste-se a um questionamento das políticas públicas para a inclusão social na educação superior e até mesmo dos ideais em si da inclusão social (VALOR ECONÔMICO, 2019; FRIGOTTO, 2017). Ou seja, o quadro apresentado por esta revisão não 
é estático ou perene, mas segue em transformação nos últimos anos - e possivelmente em retrocesso.

Um importante resultado do artigo é a percepção de que, a partir do mapeamento realizado dos trabalhos existentes que cobrem a mudança do perfil dos estudantes de graduação no Brasil entre 2011 e 2015, há uma base de dados rica e ainda pouco explorada para analisar tal fenômeno: a Pesquisa Nacional por Amostra de Domicílios (PNAD), realizada pelo Instituto Brasileiro de Geografia e Estatística, que ficou vigente até 2015 (sendo substituída pela Pesquisa Nacional por Amostra de Domicílios Contínua, que teve início em 2012). A análise do perfil dos estudantes e de suas famílias a partir da PNAD pode jogar luz em outros aspectos da mudança do perfil dos estudantes, sendo uma base de dados anual, de abrangência nacional e que traz dados de estudantes matriculados no setor público e privado. Há muito enfoque nas pesquisas nos estudantes do setor público, mas seria interessante construir um perfil dos estudantes de graduação como um todo (público e privado), dado que no período analisado muitas políticas públicas com enfoque na inclusão também foram ampliadas no setor privado. Assim, a partir da PNAD seria possível construir um perfil dos estudantes da ES ano a ano que conjugasse dados de renda, raça/cor e distribuição regional para o período analisado.

\section{Referências}

ANDIFES. Pesquisa perfil discente ANDIFES. Brasília: Andifes, 2016. Disponível em: https://goo.gl/Y5BufN. Acesso em: 27 out. 2016.

CAMPELLO, Tereza. Faces da desigualdade no Brasil: um olhar sobre os que ficam para trás. Brasília: Clacso, Flacso e Agenda Igualdade, 2017. Disponível em: http://flacso.org.br/?publication=faces-da-desigualdade-no-brasil-um-olhar-sobre-os-queficam-para-tras. Acesso em 27 fev. 2020.

CARVALHO, Igor. Dez anos de cota nas universidades: o que mudou? In.: OUTRAS Palavras, São Paulo, 2014. Disponível em: https://outraspalavras.net/outrasmidias/dez-anosde-cotas-nas-universidades-o-que-mudou/. Acesso em: 3 abr. 2018

COSTA, Danilo de Melo et al. Aspectos da reestruturação das Universidades Federais por meio do Reuni: um estudo no Estado de Santa Catarina. Revista Gestão Universitária na América Latina, Florianópolis, SC, Edição especial, 2011.

DUBET, François. Qual democratização do ensino superior? Caderno CRH, Salvador, BA, v. 28, n. 74, maio/ago. 2015.

ENADE. Enade 2017: resultados e indicadores. Brasília: INEP, 2018. Disponível em: https://goo.g1/H6WVPC. Acesso em: 10 out. 2018. 
FAGNANI, Eduardo. O fim do breve ciclo da cidadania social no Brasil (1988-2015). Texto para Discussão, Campinas, n. 308, 2017. Disponível em:

https://www.eco.unicamp.br/images/arquivos/artigos/3537/TD308.pdf. Acesso em: 14 jan. 2019.

FERES JÚNIOR, João et al. O impacto da Lei n ${ }^{\circ} 12.711$ sobre as universidades federais. Levantamento das políticas de ação afirmativa. In.: GEMAA, Rio de Janeiro, 2013. Disponível em: http://gemaa.iesp.uerj.br/wp-content/uploads/2018/03/LevantamentoGEMAA-1b.pdf. Acesso em: 22 fev. 2020.

FONAPRACE. IV Pesquisa do perfil socioeconômico e cultural dos estudantes de graduação das instituições federais de ensino superior brasileiras. Brasília: Andifes, 2014. Disponível em: 〈https://goo.gl/dyY15t>. Acesso em: 1 abr. 2018.

FRIGOTTO, Gaudêncio (org.). Escola "sem" partido: esfinge que ameaça a educação e a sociedade brasileira. Rio de Janeiro: UERJ, LPP, 2017.

GUERRA, Alexandre; SILVA, Ronnie Aldrin; OLIVEIRA, Ana Luíza Matos de. Variação da desocupação no Brasil (2016-2017): apontamentos sobre a desigualdade regional e de gênero. In: TEIXEIRA, Marilane Oliveira et al. (orgs.). Contribuição crítica à reforma trabalhista. Campinas: CESIT/Unicamp, 2017. p. 215-236.

GUIMARÃES, Raquel et al. De onde vim e até onde vou: uma análise preliminar da desigualdade socioeconômica e entrada no Ensino Superior brasileiro. In.: CEDEPLAR, Belo Horizonte, 2010. Disponível em:

http://www.cedeplar.ufmg.br/pesquisas/td/TD\%20414.pdf. Acesso em: 4 abr. 2018.

IBGE. Síntese de Indicadores Sociais 2014. Brasília: IBGE, 2014. Disponível em: https://goo.gl/Njqig8. Acesso em: 23 mai. 2015.

ISTOÉ. "Brasil vai enterrar modelo econômico social-democrata", diz Paulo Guedes. Istoé, São Paulo, 2018. Disponível em: https://goo.gl/3bwfUK. Acesso em: 9 jan. 2019.

MAZZA, Débora. Educação, trabalho e concentração urbana no parque tecnológico de Campinas. Cadernos CERU, São Paulo, SP, v. 26, n. 2, 2015.

OCDE. Education at a Glance 2018. OECD Indicators. Paris: OECD Publishing, 2018. Disponível em: https://goo.gl/SFtr94. Acesso em: 28 dez. 2019.

OLIVEIRA, Ana Luíza Matos de. Educação Superior brasileira no início do século XXI: inclusão interrompida? 2019. Tese (Doutorado) - Universidade Estadual de Campinas, Campinas, 2019.

OLIVEIRA, Romualdo Portela de; ARAUJO, Gilda Cardoso de. Qualidade do ensino: uma nova dimensão da luta pelo direito à educação. Revista Brasileira de Educação, Rio de Janeiro, RJ, n. 28, jan./abr. 2005. 
RISTOFF, Dilvo. O novo perfil do campus brasileiro: uma análise do perfil socioeconômico do estudante de graduação. Avaliação, Campinas; Sorocaba, SP, v. 19, n. 3, p. 723-747, nov. 2014. Disponível em: https://www.scielo.br/scielo.php?pid=S1414-

40772014000300010\&script=sci_abstract\&tlng=pt. Acesso em: Acesso em: 29 jan. 2019.

ROSSI, Pedro et al. Austeridade fiscal e o financiamento da educação no Brasil. Educação \& Sociedade, Campinas, SP, v. 40, p. 1-20, 2019.

UNIVERSIDADE para todos não existe. Valor Econômico, São Paulo, 2019. Disponível em: https://goo.gl/g74oEV. Acesso em: 29 jan. 2019.

VIEIRA, Danilo Jorge. Desenvolvimento regional, C\&T e ensino superior: notas sobre o contexto recente do Brasil e da Bahia. Bahia Análise \& Dados, Salvador, BA, v. 26, n. 1, 2016. 